\title{
Pembangunan Buku Digital INTERAKTIF KANAK-KANAK DI MALAYSIA: Bersediakah Penerbit?
}

\author{
Rosmani Omar \\ University of Malaya \\ rosmaniomar77@gmail.com \\ Siti Ezaleila Mustafa \\ University of Malaya \\ ezaleila@um.edu.my
}

\section{ABSTRACT \\ DEVELOPMENT OF INTERACTIVE DIGITAL BOOK FOR CHILDREN IN MALAYSIA: ARE THE PUBLISHERS PREPARED?}

\begin{abstract}
In Malaysia, the development of information and communication technology (ICT) has created an impact on children's book in the publishing world. Subsequent to this development, local book publishers were challenged to produce reading material in interactive digital form for children. Recognizing the importance of ICT and the benefit brought to the society, the government has implemented both the National Creative Industry Policy (DIKN) and the Malaysian Education Development Plan (2013-2025). Under this policy, players in the broadcasting and publishing industry in Malaysia were encouraged to develop the country's creative industry in order to raise the Gross Domestic Product (GDP). Towards the efforts in achieving this goal, how far is the preparation of the publishers in the country to publish interactive digital books for children? This is because the number of publications until 2017 is still small. Through in-depth interviews with the management of children's book publishers, some publishers sought to bring the organization's direction towards the publication of interactive digital books, but a few were found to be reluctant to change. In conclusion, they will do well with the support of all parties in order to strive for the publication of children's interactive digital books via the online platform.
\end{abstract}

Keywords: Replica digital books, interactive digital books, e-readiness, platform, $e P u b$

\section{PENGENALAN}

Perkembangan teknologi digital dilihat telah mengubah operasi dan pengurusan kandungan, termasuk aktiviti yang berkaitan dengan penjualan dan pemasaran buku (Fadli \& Md. Sidin, 2016). Sesuai dengan perkembangan tersebut, penerbit berusaha untuk menerbitkan 
pelbagai format buku, termasuk buku digital bagi bersaing dalam pasaran digital. Tambahan pula, bagi Rick Richer, mantan Presiden Penerbitan Kanak-kanak Simon \& Schuster, "We're enetering into a new interactive art form." Malah, pasaran buku untuk golongan muda dikatakan paling cepat mengalami perubahan kerana kini elemen interaktiviti dan personalisasi mula membentuk semula segmen buku kanak-kanak (Harvey, 8 Disember 2015).

Ini disebabkan buku digital telah berkembang daripada platform yang hanya memaparkan buku bercetak dalam versi digital yang mudah kepada alatan yang kini menyokong pengalaman multimedia dan interaktif yang tinggi. Secara minimumnya, penambahan multimedia kepada buku kanak-kanak termasuklah sekurang-kurangnya pembacaan lisan terhadap teks penceritaan. Malah, ia mungkin melibatkan elemen yang lazimnya tidak digunakan pada buku bercetak seperti video aksi secara langsung, grafik digital, animasi, muzik, kesan bunyi dan interaktiviti teks (Smeets \& Bus, 2013). Kini, buku ini dikenali juga sebagai "buku aplikasi" - beroperasi sebagai kategori jualan - yang direka untuk peranti skrin sentuh seperti komputer tablet dan telefon pintar (Sargeant, 2015).

Penjualan buku digital kanak-kanak menunjukkan peningkatan kerana kemajuan dalam teknologi di samping peningkatan pembacaan di skrin berbanding dengan buku sebenar. Laporan The Telegraph menyatakan bahawa ibu bapa membeli banyak buku digital untuk anak-anak mereka memandangkan generasi baharu ini sudah semakin biasa membaca di skrin iPad atau Kindle. Oleh sebab itu, jumlah buku kanak-kanak, termasuk buku cerita bergambar, yang tersedia di Internet dan menerusi aplikasi dan media digital yang lain menunjukkan peningkatan.

Industri buku digital atau e-buku di Malaysia walaupun masih kecil dari segi syer pasaran, kepesatan dalam penembusan Internet dan telefon pintar yang tinggi, inisiatif pembentukan perpustakaan digital yang ekstensif dan pelan kerajaan dalam penghasilan buku teks digital menjelang 2016, dilihat sebagai sesuatu yang tidak boleh diabaikan oleh penerbit tempatan. Oleh itu, kajian ini dilakukan untuk mengetahui sejauh mana penerbit di Malaysia bersedia dari segi ekonomi dan sumber manusia dalam memenuhi trend ini an pada masa yang sama meningkatkan kandungan kreatif tempatan untuk golongan muda yang merupakan peribumi digital.

Kajian berkaitan dengan kesediaan penerbit dalam pembangunan buku digital interaktif kanak-kanak dianggap penting kerana apabila berlakunya perubahan teknologi daripada buku bercetak kepada buku digital, pihak yang terlibat dalam industri pembukuan konvensional negara perlu mempunyai tenaga pekerja yang menguasai penerbitan buku digital sebagai langkah untuk mengikuti perkembangan teknologi penerbitan. Wilson (2014) mengajukan persoalan tentang bagaimanakah penerbit akan menyepadukan sistem mereka untuk menerbitkan buku bercetak dan buku digital secara serentak? Biarpun masa depan penerbitan buku digital masih sangat spekulatif, penerbit harus mempunyai daya untuk menerbitkan buku konvensional dan digital pada suatu-suatu masa bagi memastikan industri penerbitan tidak tenggelam begitu sahaja. Penerbit perlu bersiap sedia dari pelbagai aspek dan aset penerbitan, misalnya dari sudut faktor ekonomi atau sumber kewangan atau modal, infrastruktur teknikal, sosial, polisi perundangan, sumber manusia dan pengurusan (Toufani \& Montazer, 2011). 


\section{TINJAUAN PERSURATAN}

Kajian Scholastic (2013) menunjukkan bahawa 46\% kanak-kanak telah membaca e-buku atau buku digital. Sebanyak $54 \%$ ibu bapa mengatakan bahawa anak-anak mereka yang berumur dua tahun hingga13 tahun membaca buku digital, dengan $85 \%$ membacanya sekurang-kurangnya sekali seminggu. Kesan daripada perkembangan pembacaan secara digital telah memberikan cabaran kepada penerbit untuk mengetengahkan bahan bacaan kanak-kanak dalam bentuk digital interaktif dan menyeronokkan. Malah, penerbit perlu mencari kandungan yang segar dan menarik untuk bersaing dengan pelbagai aktiviti digital yang ditawarkan, terutamanya permainan dan komunikasi kanak-kanak dengan rakanrakan mereka mengikut peringkat umur agar dapat menarik minat mereka untuk membaca (Farrington, 2013). Perkara ini perlu dititikberatkan kerana bahan bacaan yang mengandungi isi atau ilmu yang baik mampu membentuk akhlak dan jati diri kanak-kanak dan dapat direalisasikan melalui pendedahan bahan bacaan yang baik (Maisarah \& Latifah, 2012).

Tambahan lagi, dalam perkembangan teknologi digital dan dunia pembacaan digital, kanak-kanak yang terdedah dengan persekitaran digital turut memilih buku dalam bentuk digital untuk tujuan pembacaan dan kemanfaatan mereka. Buku digital dikeluarkan dan disimpan secara elektronik dan bukan dalam bentuk cetakan. Proses penerbitan buku tersebut melibatkan bantuan penggunaan komputer untuk mencari, membentuk, menyimpan dan mengemas kini kandungan maklumat kepada khalayak. Kualiti yang terhasil sama seperti penerbitan biasa (Saxena, 2009). Malah, tumpuan juga kini diberikan kepada pelaburan realiti maya atau augmented reality kerana dikatakan boleh memacu pertumbuhan kepada \$120 bilion pada tahun 2020 (Martín-Gutiérrez, Mora, Añorbe-Díaz, \& González-Marrero, 2017).

Bagi Wilson (2014), perkembangan baharu penerbitan digital mempunyai sudut yang positif kepada penerbit kerana mereka boleh mendapat manfaat ekonomi yang signifikan daripada pengurangan kos pencetakan dan pengedaran, di samping berupaya menjual produk mereka secara terus kepada pengguna. Selain itu, penerbitan buku digital bersesuaian dengan tuntutan zaman yang berkembang menerusi teknologi. Oleh sebab itu, kesediaan penerbit untuk melakukan perubahan dalam perniagaan mereka adalah penting.

Kajian lepas oleh para sarjana berkaitan kesediaan elektronik (e-kesediaan) dilakukan dalam pelbagai bidang seperti e-perniagaan (Huang, Huang, Zhao \& Huang, 2004; (Md. Rakibul \& Boateng, 2017), pelaksanaan e-kerajaan (Mustafa, Nor Zairah \& Asma, 2017; Rao, 2017; Khaemba, Muketha \& Matoke, 2017), e-pembelajaran (Ndungu, Maweu \& Mwenja, 2017), dan industri kecil dan sederhana serta e-dagang (Abdulhakeem, Edwards \& McDonald, 2017). Terdapat juga kajian dalam konteks Malaysia seperti e-perbankan (Chai, 2005), e-dagang (Saif \& Rizwan, 2016), industri kecil dan sederhana (Selvarajah \& Hajariah, 2017), e-pengguna (Roy \& Upadhyay, 2017), pengurusan e-dagang (Syed, Md. Yunus \& Mohd. Fauzi, 2011).

Dalam bidang penerbitan, kajian berkaitan e-kesediaan dilakukan oleh Toufani (2009), Toufani dan Montazer (2011), dan Rozilah, Siti Ezaleila dan Hamedi (2018). E-kesediaan merujuk kepada ukuran sejauh mana sesebuah negara, negara atau ekonomi mungkin bersedia, sanggup atau bersedia untuk mendapat manfaat yang timbul daripada perkembangan teknologi maklumat dan komunikasi (Dada, 2006; Mutula \& Brakel, 2006). Namun, menurut Chouri et al. (2003), e-kesediaan boleh membawa maksud yang berbeza untuk orang yang berbeza, mengikut konteks yang berbeza dengan tujuan yang berbeza. Konsep e-kesediaan telah dirangka pada tahun 1990 bagi menyediakan satu rangka kerja 
dalam menilai tahap jurang digital yang wujud antara negara yang kurang membangun dengan negara yang telah membangun (Mutula \& Brakel, 2006 dlm. Toufani \& Montazer, 2011).

Walaupun terdapat pelbagai definisi e-kesediaan, umumnya, ia mengukur tahap pembangunan infrastruktur, ketersambungan, literasi komputer, akses internet, aplikasi dan perkhidmatan, kelajuan rangkaian, kualiti dan akses rangkaian polisi teknologi maklumat dan komunikasi, program latihan teknologi maklumat dan komunikasi, sumber manusia, literasi komputer, dan kandungan yang relevan (Toufani, 2009). Kajian Toufani (2009), Toufani dan Montazer (2011) mendapati bahawa kekurangan kewangan, sumber manusia dan infrastruktur teknikal memberikan implikasi emosi kepada penerbit di Iran dalam usaha menerbitkan buku digital. Oleh itu, pihak pengurusan harus melakukan pelaburan dan mempunyai dasar yang jelas dan perancangan ke arah memperluas e-penerbitan di syarikat. Kajian Rozilah, Siti Ezaleila dan Hamedi (2018) pula menunjukkan hanya sebilangan kecil penerbit di Malaysia yang bersedia untuk menerbitkan sekurang-kurangnya senaskhah buku digital, malah majoriti penerbit mengambil pendekatan tunggu dan lihat dalam memutuskan keputusan untuk melibatkan diri dalam penerbitan buku digital atau sebaliknya.

Perubahan tidak dapat dielakkan, terutama dalam era pendigitan dan analitik data raya yang menjana transformasi perniagaan dan masyarakat. Dalam usaha memperkembang perusahaan dan merebut peluang yang ada, global mindset adalah penting (Englis \& Wakkee, 2015). Organisasi juga dapat membaiki peluang kejayaan dalam dunia yang semakin berubah dan kompetitif dengan mengintegrasikan pengurusan pengetahuan dengan strategi syarikat (Dayan, Heisig \& Matos, 2017). Namun begitu, dalam mereka bentuk, mengurus, dan melakukan perubahan, terdapat enam elemen teras yang perlu diberi perhatian, iaitu penjajaran strategik, tadbir urus, kaedah, teknologi maklumat, manusia dan budaya (Rosemann \& vom Brocke, 2014).

\section{METODOLOGI}

Kajian ini menggunakan kaedah temu bual mendalam. Temu bual dilakukan dengan pihak pengurusan dari lima buah penerbit terpilih. Dua daripadanya merupakan penerbit yang berpengalaman menerbitkan buku digital interaktif kanak-kanak (Penerbit 1 dan Penerbit 2), manakala sebuah penerbit yang melibatkan diri dalam penerbitan buku digital replika kanak-kanak (Penerbit 5) dan dua lagi ialah penerbit buku bercetak kanak-kanak (Penerbit 3 dan Penerbit 4).

\section{KERANGKA KAJIAN}

Dalam dunia penerbitan, Toufani (2009) mengambil pendekatan meneliti aspek e-kesediaan dalam penerbitan menggunakan enam konstruk: isu ekonomi dan kewangan, infrastruktur teknikal, sosial, polisi perundangan, sumber manusia dan pengurusan. Namun, kajian ini hanya melihat kesediaan penerbit dari sudut ekonomi penerbitan dan sumber manusia sahaja. Ini disebabkan elemen ini menjadi penggerak kepada pelaksanaan pembangunan buku digital memandangkan sumber modal (ekonomi) merupakan input kewangan yang dapat dibelanjakan untuk melengkapi keperluan aktiviti pengeluaran (Zawiyah, 2009) manakala sumber manusia yang profesional dalam maklumat membolehkan industri buku digital meraih pasaran yang besar dengan perancangan pilihan hasil perkhidmatan teknologi 
(Nancy, 2005). Oleh itu, kerangka konsep yang diguna pakai dalam kajian ini adalah seperti yang berikut:

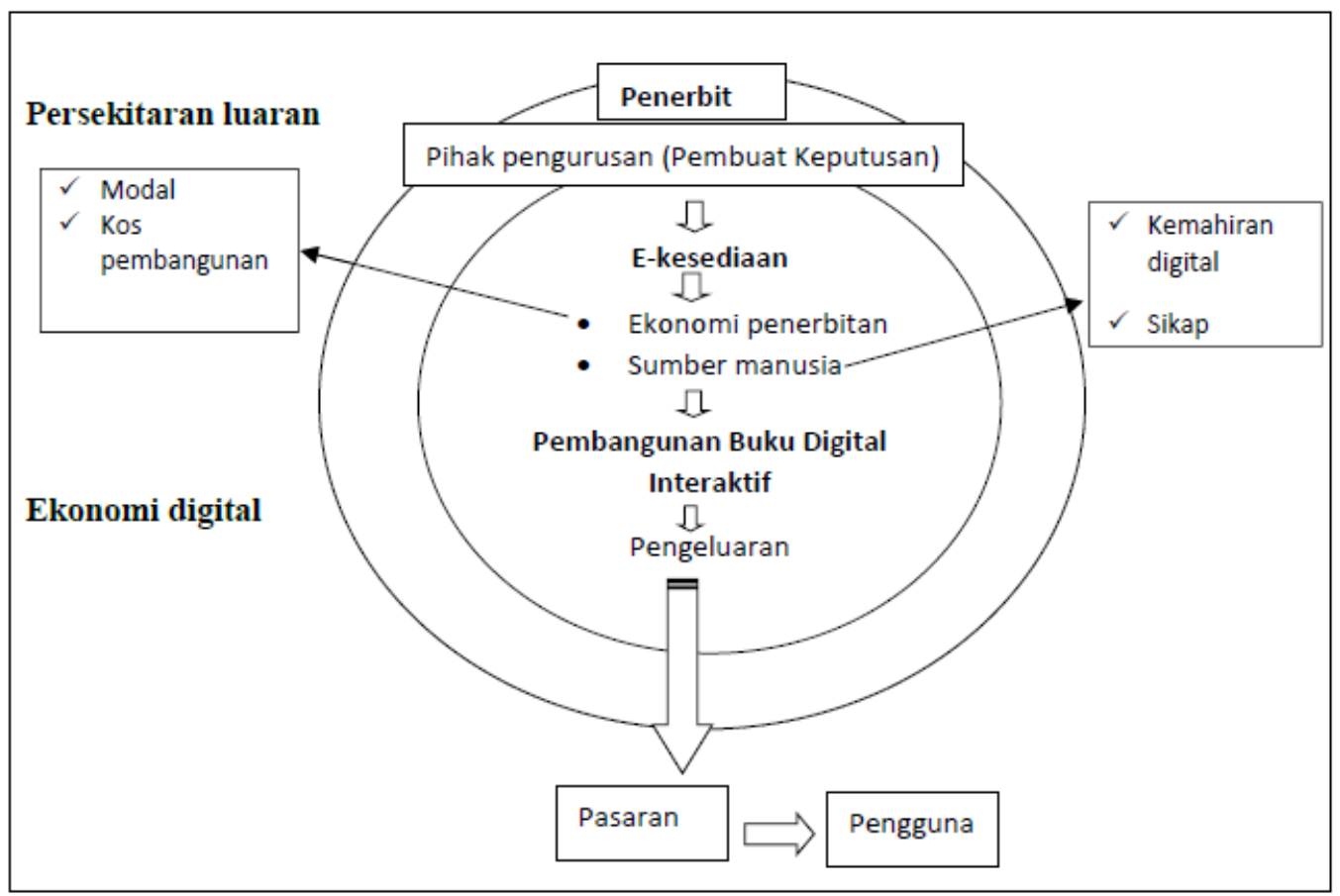

Kerangka kajian berdasarkan pengubahsuaian Model E-Kesediaan

Rajah di atas menerangkan kesediaan penerbit dari segi ekonomi dan sumber manusia dalam pembangunan buku digital interaktif kanak-kanak. Dalam kerangka kajian ini, pihak pengurusan dikatakan pihak yang mempunyai autoriti dalam membuat keputusan sama ada merancang untuk membangunkan buku digital interaktif kanak-kanak atau sebaliknya. Keputusan tersebut secara tidak langsung akan berlandaskan aset yang ada dalam organisasi penerbit, iaitu yang paling utama ialah modal dan sumber manusia. Adakah dua aspek kesediaan utama yang dimiliki oleh penerbit di Malaysia itu berupaya untuk memastikan pembangunan buku digital interaktif terlaksana dan dapat dipasarkan dan sampai kepada pengguna?

\section{ANALISIS KAJIAN}

Hasil temu bual mendapati bahawa semua penerbit berpendapat bahawa buku digital dan buku bercetak dan buku digital adalah saling melengkapi. Kedua-dua jenis buku tersebut mempunyai keistimewaannya yang tersendiri. Buku bercetak masih diperlukan terutama bagi mereka yang berada di kawasan tertentu yang tidak dilengkapi kemudahan Internet Oleh sebab itu, ada penerbit yang masih terus menerbitkan buku kanak-kanak dalam bentuk bercetak walaupun menyedari bahawa mereka perlu berubah dan mengimplimentasikan teknologi dalam penerbitan.

Walau bagaimanapun, pada masa depan kita memang ke arah tu (arah digital), tahun 2020. Dari segi persediaan, buat masa sekarang, jika diberikan skala 1 hingga 
10, kita baru pada skala ke-2. Kita perlu membuat persediaan yang mendalam. Kalau setakat PDF kami boleh menyediakannya. Untuk membangunkan bahan interaktif melibatkan kos yang tinggi, terutama pada peringkat permulaan. Walau bagaimanapun, kita perlu membuat persediaan ke arah itu.

(Penerbit 3)

Mereka berpandangan bahawa kesediaan ke arah penerbitan digital adalah penting bagi memastikan industri penerbitan tidak ketinggalan dalam arus pemodenan.

Dari jangka masa panjang kami perlu bersedia. Itulah usaha kita. Mahu atau tidak mahu kita perlu ikut trend semasa. Kami mempunyai bahagian multimedia yang khusus untuk itu. Untuk menjadi lebih mantap, kita memerlukan lebih komitmen daripada bahagian pemasaran untuk memasarkan bahan dan bahagian editorial sendiri untuk membangunkan kandungan. Jika tidak mencukupi untuk membangunkan bahan, kita boleh menggunakan sumber luar dari segi teknikal. Kepakaran kita sudah ada cuma kita perlu memantapkannya dan kita perlu bekerja secara berpasukan.

(Penerbit 1)

Buku bercetak penting. Buku digital tidak dinafikan kepentingannya. Penerbit perlu mengikut arus pemodenan supaya tidak ketinggalan.

(Penerbit 2)

Ada penerbit yang bersedia untuk membangunkan organisasi ke arah penerbitan buku kanak-kanak digital interaktif, malah berusaha untuk membawa hala tuju perancangan penerbitan mereka dengan menjalankan kerjasama dengan pihak lain untuk kepentingan pendidikan dan kepelbagaian kandungan digital negara. Penerbit 1, misalnya, menyatakan bahawa mereka telah membentangkan kertas Hala Tuju Penerbitan Digital organisasi pada peringkat tertinggi organisasi dan telah diperakukan.

Selain itu, ada penerbit yang ditemu bual menyatakan mereka sudah memikirkan persediaan-persediaan yang perlu dilakukan ke arah penerbitan buku digital interaktif kanakkanak walaupun tidak mempunyai sumber manusia yang mencukupi. Mereka menyatakan,

\begin{abstract}
Kami berminat untuk menerbitkan buku digital interaktif kanak-kanak. Kita kena mendahulukan penerbitannya daripada orang mendahului kita. Kalau dahulu Teksi, sekarang kita menjadi Grab. Pemikiran perlu berubah. Jika kita tidak berubah, suatu hari nanti, kita jangan merungut. Kita jangan salahkan takdir. Kita yang merancang takdir kita.
\end{abstract}

(Penerbit 4)

\title{
Kesediaan Ekonomi
}

Bagi memastikan kelangsungan dalam penerbitan buku digital interaktif, terdapat penerbit yang berusaha melakukan penyelidikan dan mengeluarkan modal untuk menerbitkan buku digital interaktif kanak-kanak. Bagi mereka, bahan tersebut penting untuk pengajaran dan pembelajaran kanak-kanak. Walaupun penerbitan buku digital interaktif tidak melibatkan kos pencetakan, kos pembangunan bahan multimedia-penggunaan video, audio dan 
penyediaan animasi-masih tinggi. Oleh sebab itu, ada penerbit berusaha mencari kaedah tertentu untuk memastikan buku digital tersebut dapat diterbitkan dan pada masa yang sama dapat menjimatkan kosnya. Penerbit 1, misalnya menjelaskan perkara yang berikut:

\begin{abstract}
Kita bekerjasama dengan Bahagian Sistem Maklumat kami untuk masuk dalam ekonomi digital dan bersaing dengan dunia luar. Kita merancang menjalankan projek aplikasi dan menghasilkan buku yang mengguna pakai AR. Kita mengadakan projek rintis dengan sebuah universiti. Kos untuk projek sebegitu agak tinggi. Oleh itu, kita melaksanakan kerjasama pintar kerana pihak tersebut mempunyai kepakaran dalam aspek pembangunan, dan kita mempunyai kepakaran dari segi editorial dan pembinaan kandungan.
\end{abstract}

(Penerbit 1)

Penerbit 2 pula melibatkan diri dalam projek penerbitan buku kanak-kanak digital interaktif kerana keperluan masyarakat, malah mereka tidak terlalu bergantung pada pihak luar untuk menampung kos penerbitannya. Mereka melakukan penyelidikan dan mengeluarkan modal untuk perkara tersebut walaupun tidak menjanjikan pulangan modal. Mereka perlu berusaha keras untuk memasarkannya agar dapat menampung kos penerbitan. Maka, tidak hairanlah, kos menjadi penyebab banyak syarikat yang berasaskan multimedia untuk pembelajaran tidak dapat bertahan dalam industri. Ini disebabkan mereka tidak berkemampuan untuk membayar kos editor, penulis, pengatur cara, pereka grafik dan animator profesional.

Walaupun terdapat dana daripada kerajaan dalam menggalakkan pembangunan kandungan, dana tersebut lebih tertumpu kepada animasi. Untuk penerbitan buku digital, tiada dana khusus yang diberikan. Hasil temu bual mendapati Penerbit 1 dan Penerbit 3 pernah memohon dan memperoleh dana daripada kerajaan pada tahun-tahun awal pengenalannya. Namun dana tersebut agak terhad dan tidak merangkumi semua penerbit. Oleh itu, mereka berharap agar peruntukan itu dinaikkan bagi menggalakkan pemain industri pembukuan membangunkan kandungan bahan digital dan pada masa yang sama mengurangkan penerbit mengimport bahan kandungan digital dari luar negara. Walaupun bagaimanapun penerbit mengakui bahawa mereka tidak boleh mengharapkan dana kerajaan semata-mata; mereka mahu kerajaan memberikan sokongan bagi mewujudkan situasi menang-menang.

Walau bagaimanapun, bagi Penerbit 5, kos penerbitan buku digital interaktif bukan masalah utama. Mereka berpandangan bahawa kosnya adalah sederhana, tidak terlalu tinggi, sesuai dengan kandungan yang ingin dibangunkan. Oleh itu, mereka tidak mempunyai masalah dari segi modal untuk pembangunan buku digital. Permasalahan utama yang dihadapi oleh mereka ialah tiadanya pasaran buku digital tersebut.

Kekhuatiran tentang pasaran juga ditimbulkan oleh Penerbit 3 dan Penerbit 5. Keadaan ini juga berlaku pada buku bercetak yang menyaksikan penurunan pembelian buku di pesta buku yang diadakan. Penjualan buku di kedai buku juga mengalami kemerosotan kerana orang ramai dikatakan membeli buku secara dalam talian. Dari aspek buku digital pula, yang mendapat sambutan ialah buku novel. Menurut Penerbit 5,

Buku kanak-kanak sambutannya sangat rendah, bukan setakat buku digital malahan buku konvensional juga apabila diletakkan di kedai buku, selepas empat bulan kemudian, buku tersebut dihantar semula kepada penerbit kerana tidak terjual. 
Dalam penerbitan buku digital, terdapat penerbit yang pada mulanya bersemangat untuk menerbitkan buku digital kanak-kanak, namun disebabkan tiadanya pasaran, mereka tidak meneruskan usaha tersebut.

\begin{abstract}
Pada mulanya kami bersemangat untuk menerbitkan buku digital kanak-kanak, sebab kami berpandangan bahawa kami yang terawal menerbitkan buku bahasa Melayu dalam bentuk digital. Kami ini penerbit swasta. Apabila tiada yang membelinya, lama-lama kami lemah. Penerbitan memerlukan permintaan dan penawaran. Jika tiada permintaan, tiada guna kami menerbitkannya.
\end{abstract}

(Penerbit 5)

Kekhuatiran yang ditimbulkan terhadap permintaan buku konvensional memberikan kesan emosi kepada kesediaan penerbit untuk menerbitkan buku digital. Hal ini disebabkan penerbitan buku digital memerlukan sambutan terhadap pembeliannya walaupun Penerbit 4 mengakui bahawa terdapat kebaikan buku digital, iaitu untuk mengurangkan beban pengguna membawa buku dan terdapat kelebihan untuk pengguna mengakses pelbagai bahan melalui alatan (gadget). Penerbit tersebut juga berpendapat bahawa penerbitan konvensional masih diperlukan oleh masyarakat terutama di kawasan pedalaman kerana tidak semua masyarakat memiliki alatan. Pemilikan alatan juga memberikan kesan emosi kepada kanak-kanak yang tidak mampu memilikinya.

\title{
Kesediaan Sumber Manusia
}

Dari segi penerbitan buku kanak-kanak di Malaysia, peratusan sumber manusia yang terlibat dalam pembangunan buku digital yang terdapat dalam organisasi penerbitan di negara ini masih kecil. Penerbit 1 menyatakan bahawa sumber manusia yang mempunyai kemahiran dalam bidang ini di organisasi hanya dalam lingkungan 20\%. Namun demikian, pihak mereka tidak mempunyai masalah untuk membangunkan buku digital kanak-kanak kerana mereka boleh bekerjasama dengan pihak luar.

Terdapat juga penerbit yang ditemu bual menyatakan bahawa untuk membangunkan buku digital interaktif penerbit perlu bersedia untuk memiliki sumber manusia yang mahir, misalnya dalam pembangunan aplikasi. Walaupun demikian, sumber manusia yang ada perlu diberikan latihan untuk meningkatkan kemahiran mereka dalam konteks pembangunan kandungan digital. Hal ini disebabkan perkara berikut:

... masalah sekarang ialah sumber manusia yang dibekalkan tidak memenuhi pasaran. Terdapat staf kami dalam bidang animasi pada peringkat diploma dan ijazah dalam bidang multimedia. Kemahiran yang staf tersebut ada untuk membuat aplikasi terlalu ringkas (simple). Kemahiran yang dipelajari di universiti tidak cukup untuk membangunkan aplikasi. ... bagi meningkatkan kemahiran, staf kami belajar melalui senior dan maklumat daripada Internet.

(Penerbit 2)

Menurut Penerbit 1, dalam pembangunan buku digital, sumber manusia juga perlu diberikan pendedahan tentang penyediaan bahan dalam format ePub sebelum didedahkan dengan kemahiran pembangunan interaktif. Ini disebabkan terdapat penerbit yang tidak menukarkan bahan buku kanak-kanak kepada format ePub kerana kekurangan sumber manusia dan 
mereka menyerahkannya tugas berkenaan kepada pihak pembangun sebelum dimuat naik ke platform dalam talian. Oleh itu, mereka mencadangkan pihak pengurusan tertinggi memberi perhatian kepada pembangunan sumber manusia dalam digital-dari aspek latihan dan peruntukan untuk latihan. Malah, staf yang ada pada juga perlu dihantar ke pusat latihan industri untuk meningkatkan kemahiran mereka.

Bagi meningkatkan kemahiran staf, Penerbit 2 dan Penerbit 5 memberikan galakan kepada staf atau menghantar staf mereka untuk menghadiri kursus-kursus yang diadakan di dalam negara. Namun, menurut Penerbit 2, kebanyakan kursus yang dihadiri melibatkan pengetahuan yang sedia ada pada staf mereka. Menurutnya, dalam konteks hari ini misalnya, kursus-kursus berbentuk aplikasi perlu ditawarkan kepada penerbit untuk keperluan pembangunan buku digital interaktif kanak-kanak. Bagi Penerbit 3, walaupun tidak bersedia ke arah penerbitan buku digital, mereka berpendapat bahawa perkembangan teknologi perlu diterokai untuk meningkatkan pengetahuan di samping memastikan industri penerbitan terus bertahan.

Hal ini disebabkan kebanyakan penerbit buku bercetak mempunyai staf lama yang berkemungkinan kurang mahir dalam teknologi maklumat dan komunikasi. Oleh sebab itu, perubahan gaya kerja daripada konvensional kepada digital bukannya sesuatu yang mudah kerana membabitkan perubahan oleh pihak pengurusan organisasi dan staf. Kedua-dua pihak ini perlu mempunyai kesediaan dalam pelbagai aspek untuk melakukan perubahan dalam organisasi. Penerbit 5 menyatakan bahawa mereka pernah menghantar staf untuk mengikuti kursus bagi meningkatkan kemahiran dalam penerbitan buku digital dan menggalakkan staf mereka membangunkan buku digital, tetapi staf tidak progresif ke arah itu. Oleh sebab itu, mereka tidak lagi menghantar staf untuk mengikuti kursus sebegitu; tambahan pula tiada perancangan untuk menerbitkan buku digital pada masa ini.

Beberapa penerbit (Penerbit 1 dan Penerbit 5) juga berpendapat bahawa sikap segelintir staf yang mewujudkan masalah turut memberikan kekangan ke arah penerbitan buku digital interaktif. Ini disebabkan ada staf yang tidak mempunyai kemahiran dalam penugasan berbilang (multi-task); ada sikap kurang menghayati kerja, terutama dalam kalangan generasi muda. Sikap sedemikian perlu diubah demi kebaikan dan meningkatkan kualiti organisasi kerja yang dilakukan. Sekiranya tidak diubah, keadaan ini akan memberikan kesan kepada perubahan kerja yang akan dijalankan bukan sahaja kepada penerbitan buku bercetak malahan kepada proses kerja buku digital.

\section{PERBINCANGAN}

Penerbitan buku digital interaktif untuk kanak-kanak adalah kecil, iaitu 60 judul berbanding lebih daripada 100 judul untuk edisi replika (Rosmani \& Siti Ezaleila, 2017). Ini menunjukkan bahawa tidak ramai yang bersedia untuk menerbitkan buku digital interaktif, sedangkan Lanksher dan Michele (2006) berpendapat bahawa dunia pengetahuan kelihatan janggal jika hanya tertakluk kepada media cetak. Kajian Booknet Canada menunjukkan bahawa akses kanak-kanak terhadap peranti digital meningkat selari dengan peningkatan usia. Malah, hampir 50\% ibu bapa mempunyai aplikasi yang berkaitan dengan buku pada peranti mereka untuk kegunaan anak-anak. Malah, kerajaan Malaysia juga telah merancang untuk menambah nilai dalam kepelbagaian bahan pengajaran dan pembelajaran berasaskan teknologi dalam Pelan Pembangunan Pendidikan Malaysia. 
Hasil temu bual dengan lima buah penerbit menunjukkan bahawa terdapatnya pandangan yang berbeza tentang kesediaan syarikat dalam penerbitan buku digital interaktif kanak-kanak. Dari aspek ekonomi, masalah yang ketara ialah kos dan pasaran. Penerbit yang terlibat dengan penerbitan buku kanak-kanak bercetak perlu menanggung kos operasi yang semakin meningkat dan sekiranya mereka menerbitkan buku dalam format interaktif, kosnya akan bertambah. Oleh itu, penerbit mengharapkan dana atau sokongan daripada kerajaan sekiranya Malaysia mahu meningkatkan industri kreatifnya. Ini disebabkan syarikat tidak mampu menjana sumber dalaman yang mencukupi, mereka akan mencari sumber dari luar (Fligstein \& Freeland, 1995).

Kebimbangan tentang pasaran muncul dalam kalangan penerbit, seperti Penerbit 1 dan Penerbit 2, yang sudah mempunyai pengalaman dalam menerbitkan buku digital interaktif kanak-kanak. Walaupun buku yang diletakkan di Google Play Book dan e-Sentral mendapat pembelian dari luar negara seperti Korea, Jepun dan Amerika Syarikat, jualannya tidak begitu menggalakkan. Malah penjualan buku bercetak juga menghadapi masalah dalam keadaan ekonomi pada masa ini. Faktor ekonomi memberi pengaruh kepada mana-mana perniagaan sama ada membantu mahupun menghalang sesebuah syarikat mencapai objektifnya. Maka, syarikat perlu mengambil kira faktor ini dalam memutuskan sesuatu keputusan perniagaan (Bush, 2016).

Sumber manusia juga merupakan elemen atau faktor penting dalam menentukan kesediaan syarikat dalam merealisasikan penerbitan dan pembangunan buku digital. Hasil temu bual, hampir semua penerbit menghadapi masalah berkaitan dengan sumber manusia sehingga menjadi halangan kepada penerbit untuk menerbitkan buku digital interaktif. Keadaan ini sama dengan kajian Toufani (2009) yang menunjukkan bahawa faktor sumber manusia, di samping bahagian pengurusan, memerlukan perhatian yang lebih. Penerbit memerlukan sumber manusia yang berkemahiran di samping memiliki sikap yang proaktif dan bersedia melakukan pelbagai tugas. Ini disebabkan akses kepada tenaga kerja yang mahir dan berpendidikan merupakan salah satu faktor mengukur e-kesediaan (Bui, Sankaran \& Sabastian, 2003, Toufani, 2009). Oleh sebab itu, strategi sumber manusia perlu disejajarkan dengan strategi perniagaan syarikat (Kateb \& Ahmadi, 2018).

Walaupun Malaysia mencatat skor yang tinggi dalam Indeks Pembangunan Manusia yang tinggi, Malaysia masih di belakang Singapura dan Brunei. Oleh sebab itu, kursus yang relevan dengan keperluan industri semasa diperlukan, terutama di peringkat pengajian tinggi. Kursus berkaitan dengan animasi, misalnya perlu diperluas jika mahu melahirkan sumber manusia yang berkemahiran dalam pembangunan bahan interaktif. Di Malaysia terdapat dua buah universiti yang mempunyai program animasi yang menawarkan sarjana muda pengkhususan dalam bidang animasi dan 16 buah universiti yang menawarkan program yang mempunyai komponen animasi (Fadli \& Md Sidin, 2010). Pendidikan sama ada secara formal atau tidak formal diperlukan dalam usaha mewujudkan lebih ramai sumber manusia terlatih atau berkemahiran di samping meningkatkan kemahiran sumber manusia yang sedia ada.

\section{KESIMPULAN}

Jumlah dan kepelbagaian jenis penerbitan dalam industri pembukuan di sesebuah negara baik dalam bentuk bercetak atau digital secara tidak langsung akan menggambarkan kearifan dan ketamadunan sesebuah masyarakat. Oleh itu, penerbit perlu bersedia dalam pembangunan buku digital interaktif dalam menghadapi Revolusi Perindustrian 4.0. 
Oleh sebab itu, perubahan adalah elemen penting dalam pembangunan dan kemandirian sesebuah organisasi atau perniagaan dalam persekitaran pembangunan teknologi dan digital. Dalam hal ini, tanggapan peluang pasaran, sumber manusia berkemahiran dan sokongan kerajaan mempunyai kaitan dengan fisibiliti dan keinginan sesebuah syarikat untuk memulakan perniagaan atau perubahan (Begley, Tan, \& Schoch, 2005).

Perubahan ini memerlukan sokongan pelbagai pihak, termasuk daripada kerajaan bagi mewujudkan persekitaran yang kondusif - termasuk dari aspek ekonomi dan infrastruktur pendidikan-untuk industri penerbitan negara. Pelbagai pihak perlu mengatur gerak langkah dan bekerjasama antara satu sama lain bagi memastikan lebih banyak penerbit bersedia membangunkan buku digital interaktif kanak-kanak di Malaysia. Usaha menyebarluaskan kewujudan buku digital interaktif kanak-kanak harus diadakan secara berterusan bagi memperlihatkan kewujudannya. Melalui usaha tersebut diharapkan agar terdapat sambutan terhadap buku digital interaktif kanak-kanak dan dunia pembacaan kanak-kanak menjadi lebih menyeronokkan dengan penampilan kandungan yang menarik dan ilmu yang bernilai.

\section{RUJUKAN}

Abdulhakeem Idris, Edwards, H. \& McDonald, S. (2017, 3-5 April). E-commerce readiness of SMEs in developing countires: A Model-Driven Systematic literature review. Dalam UKAIS 2017: 22nd Annual Conference, St Catherine's College, Oxford, UK.

Begley, T., Tan, W.L. \& Schoch, H. (2005). Politico-economic factor associated interest in starting a business: A multi-country study. Entrepreneurship Theory and Practice. 29 (1), 35-55.

Bui, T.X., Sankaran, S. \& Sebastian, I.M. (2003) A framework for measuring national e-readiness. International Journal Electronic Business, 1(1), 3-22.

Bush, T. (2016, 4 Julai). PESTLEL analysis: Economic factor affecting business. PESTLEL Analysis. https://pestleanalysis.com/economic-factors-affecting-business/

Chai, L. G. (2005). E-banking in Malaysia: Opportunity and challenges. The Journal of Internet Banking and Commerce, 10(3). http://www.icommercecentral.com/open-access/ ebanking-in-malaysia-opportunity-and-challenges.php?aid=38622

Chouri et al. (2003). Global e-readiness- for whats? http://digital.mit.edu/.../2003.05_Choucri_ Maugis_Madnick_Siegel_Global\%20e-Readiness

Dada, D. (2006). E-readiness for development countries: moving the focus from the environment to the users. The Electronics Journals on Information Systems in Developing Countries, 27, 6, 1-14. Diakses pada 31 Mei 2016 daripada http://www.ejisdc.org

Dayan, R. Heisig, P. Matos, F. (2017). Knowledge management as a factor for the building and implementation of organization strategy. Journal of Knowledge Management, 21 (2), 308-329. Doi: 10.1108/JKM-02-2016-0068

Englis, P.D. \& Wakkee, I. (2015). Managerial mindset and the born global firm. Dalam. Aard Groen, Gary Cook \& Peter van der Sijde (eds.). New technology-based firms in the new millenium. London: Emerald Group Publishing Limited.

Fadli Abdullah \& Md Sidin Ahmad Ishak. (2010). Pembangunan sektor animasi di Malaysia: Pendidikan dan latihan animasi di institut pengajian tinggi awam. Jurnal Pengajian Media Malaysia, 12 (2), 69-82. 
Fadli Abdullah \& Md Sidin Ahmad Ishak. (2016). Kesan perkembangan teknologi terhadap industri penerbitan buku di Malaysia. Jurnal Pengajian Media Malaysia, 18 (2), 71-86.

Farrington, J. (2013). Gadjet trump reading, bookseller conference hears. Diakses pada 21 Januari 2018 daripada https:/www.thebookseller.com/news/gadgets-trump-reading-booksellerconference-hears

Fligstein, N. \& Freeland, R. (1995). Theoretical and comparative perspectives on corporate organizations. Annual Review of Sociology, 21, 21-43.

Harvey, E. (2015, 8 Disember). 5 trends affecting children's literature. Book Business. https:// www.bookbusinessmag.com/article/what-we-learned-from-the-top-trends-in-childrensliterature-webinar/

Huang, J.H., Huang, W.W., Zhao, C.J. \& Huang, H. (2004). An e-readiness assesment framework and two field studies. Communications of the Association for Information System, 14(19), 364-386.

Kateb, M. \& Ahmadi, A.A. (2018). Aligning human resources and business strategy. Management Science Letters, 8, 1399-1412.

Khaemba, S.N., Muketha, G. M., \& Matoke, N. (2017). Factors affecting citizen readiness for e-goverment systems in Kenya. Journal of Research in Engineering and Applied Sciences (JREAS), 2(2), 59-67.

Lankshear, C. \& Knobel, M. (2006). New literacies: everyday practices and classroom learning. Maidenhead: Open University Press.

Maisarah Saidin \& Latifah Abdul Majid. (2012). Pembentukan jati diri kanak-kanak melalui bahan bacaan bahasa Malaysia. Jurnal Hadhari, 4 (1), 77-102.

Martín-Gutiérrez, J., Mora, C.E., Añorbe-Díaz, B. \& González-Marrero, A. (2017). Virtual technologies trends in education. EURASIA Journal of Mathematics Science and Technology Education. Diakses pada 21 Januari 2018 daripada http://www.ejmste.com/VirtualTechnologies-Trends-in-Education,75042,0,2.html

Md. Rakibul Hoque \& Boateng, R. (2017). Adoption of B2B e-commerce in developing countries: Evidence from ready made garment (RMG) industry in Bangladesh. Pacific asia Journal of the Association for Information Systems, 9(1), 55-74.

Nancy, K. H. (2005). The e-book industry today: a bumpy road becomes an evolutionary path to market maturity. The Electronic Library, 23 (1), 45-53.

Mustafa Omar M. Baeuo, Nor Zairah Ab. Rahim \& Asma Ali Mosa Alaraibi. (2017). Technology factors influencing e-government readiness. Journal of Theoretical and Applied Information Technology, 95 (8), 1637-1645.

Mutula, S. M., \& Brakel, P. (2006). An evaluation of e-readiness assessment tools with respect to information access: towards an integrated information rich tool. International Journal of Information Management, 26, 212-223.

Ndungu, R. N., Maweu, F. \& Mwenja, J. M. (2017). An e-readiness assessment of ICT integration in public primary schools in Kenya case of Nyeri County. International Journal of Computer Applications Technology and Research, 6(6), 264-268.

Rao, M.V. (2017). E-governance in India: Initiatives \& challenges. International Journal of Research in Management \& Social Science, 5(2), 33-38.

Rosemann, M. \& vom Brocke, J. (2014). The six core elements business process management. vom Brocke J., Rosemann M. (eds) Handbook on Business Process Management 1 (h. 105122). Berlin: Springer. 
Rosmani Omar \& Siti Ezaleila Mustafa. (2017). Buku digital interaktif kanak-kanak di Malaysia: Platform untuk penerbit mengupayakan pembanguan kandungan kreatif negara. International Journal of Education, Psychology and Counseling. 2( 6), 183-201.

Roy G. S. \& Upadhyay, P. (2017). Does e-readiness of citizens ensure better adoption of government's digital initiatives? A case based study. Emeraldinsight, 30 (1).

Rozilah Katan, Siti Ezaleila Mustafa \& Hamedi Mohd Adnan. (2018). The readiness of e-publishing among Malaysian book publishers. Publishing Research Quarterly, 34 (3), 362-377.

Saif-Ur-Rehman \& Rizwan Alam. (2016). A Study of Barriers to e-commerce adoption among SMEs in Malaysia. UMS, 1(1), 45-58.

Sargeant, B. (2015). What is an ebook? What is a book app? And why should we care? An analysis of contemporary digital picture books. Children's Literature in Education, 46 (4), 454-466.

Saxena, A. (2009). Electronic Publishing: Impact of ICT on Academic Libraries. Poster Papers, ICAL 2009. Diakses pada 12 Ogos 2016 daripada http:/crl.du.ac.in/ical09/papers/ index_files/ical-117_142_311_2_RV.pdf

Scholastic Inc. (2013). Kids and family reading report (4th Edition). Scholastic. Harrison Group, Diakses pada 27 Mac 2016 daripada http://mediaroom.scholastic.com/files/kfrr2013noappendix.pdf.

Selvarajah T. Krishnan \& Hajariah Hussin. (2017). E-Learning readiness on bumiputera SME's intention for adoption of online entrepreneurship training in Malaysia. Management 7 (1), 35-39.

Smeets, D \& Bus, A. (2013). Picture storybooks go digital: Pros and cons. Dlm. Susan B. Neuman \& Linda B Gambrell (Eds), Quality reading instruction in the age of common core standards (176-189). London: International Reading Association.

Syed Shah Alam, Md. Yunus Ali \& Mohd. Fauzi Mohd. Jani. (2011). An empirical study of factors affecting electronic commerce adoption among SMEs in Malaysia. Journal of Business Economics and Management, 12(2), 375-399.

Toufani, S. (2009). E-readiness assessment in Iranian B2B Enterprises. Case: Iranian Book Publishing Companies. Tesis Sarjana. Lulea University of Technology, Iran

Toufani, S., \& Montazer, G. A. (2011). E-publishing readiness assessment in Iranian publishing companies. The Electronic Library, 29 (4), 470-487.

Wilson, T. D. (2014). The e-book phenomenon: a disruptive technology. IR Information Research, Vol.19, No. 2. Diakses pada 23 Mei 2016 daripada http://www.informationr.net/ir/19-2/ paper612.html\#.V0JgidR96t8

Zawiyah Mohamad Yusof. (2009). Sains sosial E teknologi maklumat. Selangor: Pearson Malaysia Sdn. Bhd. 